\title{
Blockchain Based E-Voting System
}

\author{
B.Rahul, P.SheelaGowr, M.Latha, S.Regina Shereen, M.Vishal
}

\begin{abstract}
Building an electronic casting a ballot framework that fulfills the lawful necessities of administrators has been a test. An appropriated record innovation is an energizing mechanical headway in the Information Technology world. This paper intends to assess the utilization of block chain as administration to actualize dispersed electronic casting a ballot framework. The paper elicit ate the prerequisites of structure electronic casting a ballot framework and distinguishes the lawful and mechanical constraints of utilizing block chain as an administration for acknowledging such frameworks. The paper assesses a portion of the prominent block chain systems that offer block chain as aadministration. This paper proposes a novel electronic casting a ballot framework dependent on block chain that tends to all constraints. All the more for the most part this paper assesses the capability of dispersed record advancements through the portrayal of a contextual analysis, to be specificthe procedure of a race and actualizing a block chain-based application which improves the security and diminishes the expense of facilitating an across the nation decision.
\end{abstract}

Keywords: Block chain, Voting System, Distributed ledger technologies.

\section{INTRODUCTION}

In each vote based system, the security of a decision involves national security. The PC security field has for 10 years concentrated the conceivable outcomes of electronic casting a ballot framework, with the objective of limiting the expense of having a national race, while satisfying and expanding the security states of a decision. From the beginning of fairly choosing competitors, the casting a ballot framework has been founded on pen and paper. Supplanting the conventional pen and paper plot with another race framework is basic to restrain extortion and having the casting a ballot procedure detectable and evident[1]. Electronic casting a ballot machines have been seen as imperfect, by the security network, principally dependent on physical security concerns. Anybody with physical access to such machine can disrupt the machine, in this manner influencing all votes cast on the previously mentioned machine. Enter block chain innovation. A block chain is a disseminated, unchanging, indisputable, open record.

Revised Manuscript Received on December 30, 2019.

* Correspondence Author

B.Rahul, Student*, Department of Computer Science and Engineering, Vels Institute of Science, Technology and Advanced Studies, Chennai, Tamilnadu, India.

P.SheelaGowr, Assistant Professor, Department of Computer Science and Engineering, Vels Institute of Science, Technology and Advanced Studies, Chennai, Tamilnadu, India.

M.Latha, Assistant Professor, Department of Computer Science and Engineering, Vels Institute of Science, Technology and Advanced Studies, Chennai, Tamilnadu, India.

S.Regina Shereen, Student, Department of Computer Science and Engineering, Vels Institute of Science, Technology and Advanced Studies, Chennai, Tamilnadu, India.

M.Vishal, Student, Department of Computer Science and Engineering, Vels Institute of Science, Technology and Advanced Studies, Chennai, Tamilnadu, India.

(C) The Authors. Published by Blue Eyes Intelligence Engineering and Sciences Publication (BEIESP). This is an open access article under the CC BY-NC-ND license (http://creativecommons.org/licenses/by-nc-nd/4.0/)

\section{LITERATURE SURVEY}

\section{J. Hall, "CanBlock chain Technology solve Voting Issues"}

Each record on a block chain shows up on a shared, conveyed record, implying that everybody on the system can see and check records. For race purposes, each vote would interface with an individual voter, and any inconsistencies would be comprehended by basically surveying the record diminishing voter extortion and wiping out the "hanging chad" marvel of 2000.At a similar time, the open record would attach each vote to an individual voter, setting up a lasting, changeless record. Misrepresentation would be exceptionally far-fetched, and any unfairness would either be clear on the record or adjusted by the shared agreement network [9]. Ablock chain is likewise changeless: that is, each record on the record is lasting and unalterable. That would make examining simpler, altering practically inconceivable and lost or missing votes a relic of times gone by. Each vote would be conclusive and ensured.

A. Sandre, Hackernoon, "Blockchain Voting and Elections"

Framework includes a customer server design incorporated with a block chain framework [7]. The base prerequisite required by a voter is a cell phone or a PC with a webcam and a web association. On the off chance that these are not met substitute game plans, for example, spring up digital bistros and PCs at open structures must give access to distraught voters [2]. The proposed framework is appeared to be very cost effective when contrasted with different nations and can be actualized with existing foundation possessed by a country. Remembering every one of these components the proposed framework is an extensive arrangement that fulfills every one of the necessities mentioned by the client. The current vote framework is appeared to have huge number of issues which can prompt broad political agitation in a nation. It is essential for a majority rule government to have a straightforward casting a ballot framework that must have minimal number of obstructions for a voter to cast a ballot. The way toward casting a ballot has two stages in the old procedure, for example enrolling to cast a ballot and the way toward casting a ballot itself. The proposed framework will have an additional progression, for example the capacity for the client to confirm their vote. This is a significant advance where the client can get an affirmation of their vote. Different advances incorporate tallying the votes by the coordinator and relating if there should be an occurrence of any inconsistencies.

M.D. Castillo, "Russia Is Leading the Push for Block chainDemocracy"

Utilizing a current program called Active Citizen; the city of Moscow has been enabling inhabitants to thrown votes in favour of estimates extending from the name of their new metro train to the shade of the seats in another games field.

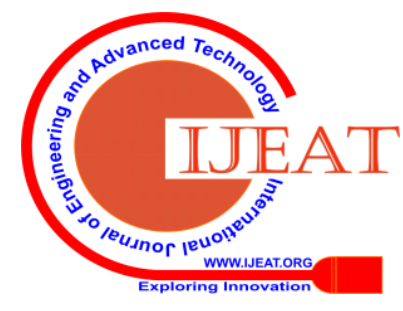




\section{Blockchain Based E-Voting System}

However, with an end goal to mitigate individuals' worries about whether to believe the city in its vote checking it's additional a private rendition of the ethereum block chain to that undertaking's design [4]. The ethereumbased stage, which enables anybody to review the opensource results, has been downloaded by in excess of 100 hub administrators since its December dispatch. One such vote signed on the ethereum stage was a measure that enabled natives to cast a ballot whether they'd pick in to be incidentally migrated while the structure they live in now was wrecked and supplanted by a more current, more pleasant structure. Furthermore, that, however Belozerov trusts there's force from government substances to receive block chain innovation for upgraded straightforwardness, yet additionally different efficiencies. What's more, that, however Belozerov trusts there's energy from government substances to embrace block chain innovation for improved straightforwardness, yet in addition different efficiencies.

\section{METHODS}

\subsection{USER}

The client must have a cell phone, pc or any gadget with a program and a forward looking camera. The client should likewise have a web association with register and vote too [3]. On the off chance that the client does not have a pc or a web association, he/she could go to an open structure, for example, a library or a school which has pcs to enlist to cast a ballot. These could be kept open throughout the day amid casting a ballot enrollment and casting a ballot days to guarantee individuals with low wellsprings of salary don't get left out.

\subsection{AUTHENTICATION SERVER}

The Authentication Server is a customary concentrated web server. It has a backend database associated with it which has the data of the considerable number of residents in the nation. This framework is utilized by individuals to enrol to vote in favour of their races. Individuals make login accounts when they register. It additionally makes accounts on the block chain framework for the clients when they vote [8]. The block chain account is utilized by the assertion server to vote in favour of a hopeful of the clients' decision. The AS additionally verifies the token gave to the approval server by the client while casting a ballot.

\subsection{ARBITRATION SERVER}

The Arbitration Server goes about as a mediator between a client and the block chain casting a ballot framework. It checks the client while casting a ballot utilizing the Authentication Server [5]. The AR is a block chain dainty customer that sends the clients vote to a block chain hub. It additionally sends the client the way to encode their vote. The AR sends the clients vote to the suitable hub to be added to the block chain. The client can check their vote utilizing the AR as a go-between.

\subsection{Blockchain system}

The block chain framework is the framework on which the genuine casting a ballot happens [6]. The clients vote is sent to the one of the hubs on the framework relying upon the heap on every hub. The hub at that point adds the exchange to the block chain relying upon the savvy gets that exist on every hub. The keen contracts are the standards that the hubs pursue to confirm as well as include the vote in the framework. Every hub pursues the brilliant contract to confirm the vote. The block chain is a private framework and isn't available to the open legitimately. The framework will right now have hub server in each state to guarantee appropriated system traffic on the framework.

\subsubsection{SYSTEM ARCHITECTURE}

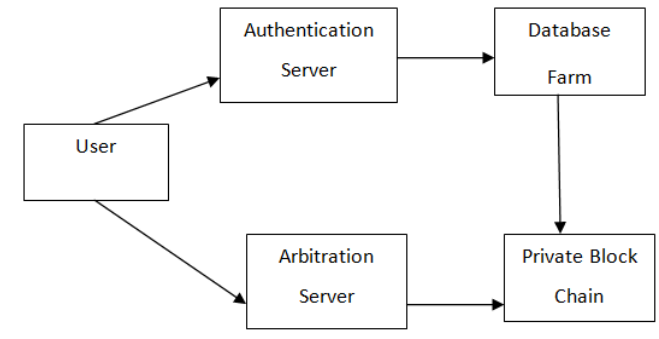

Fig 3.1

\section{RESULTS:}

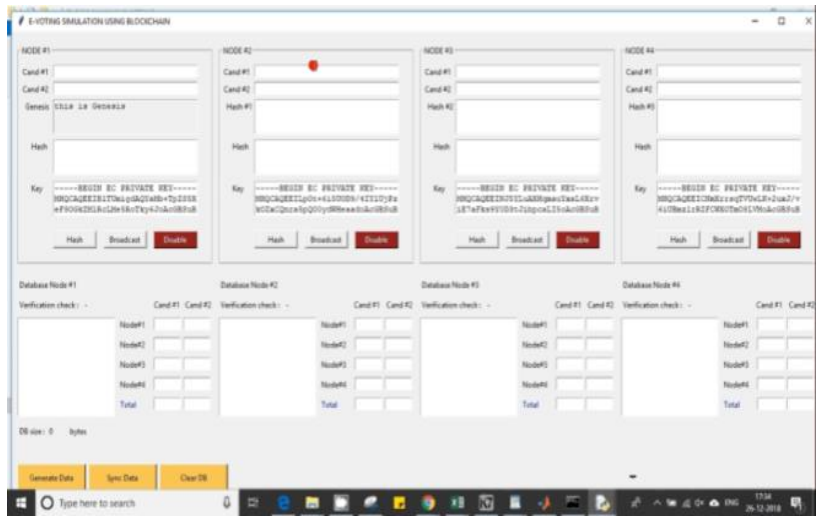

Fig 4.1: Generate Key

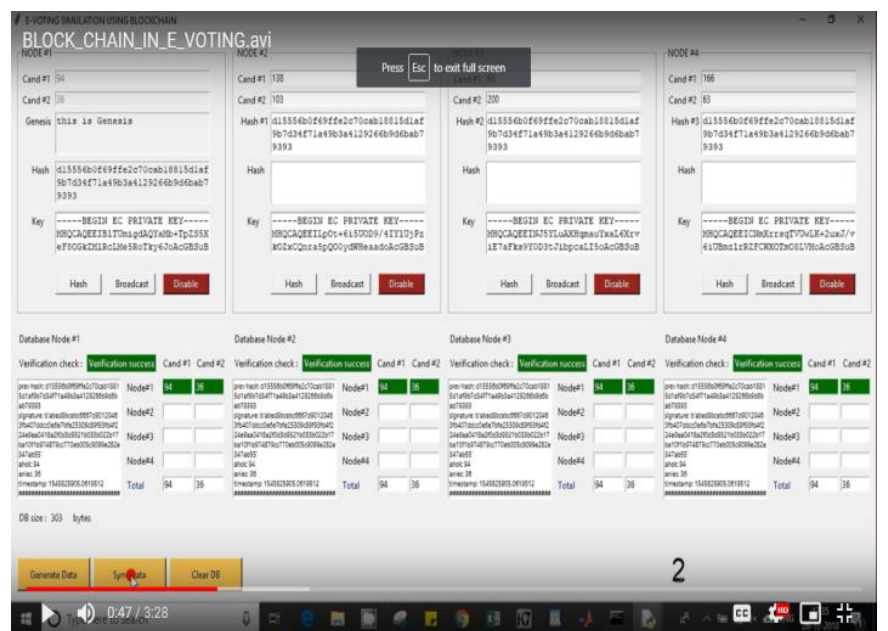

Fig.4.2:SYNC DATA 


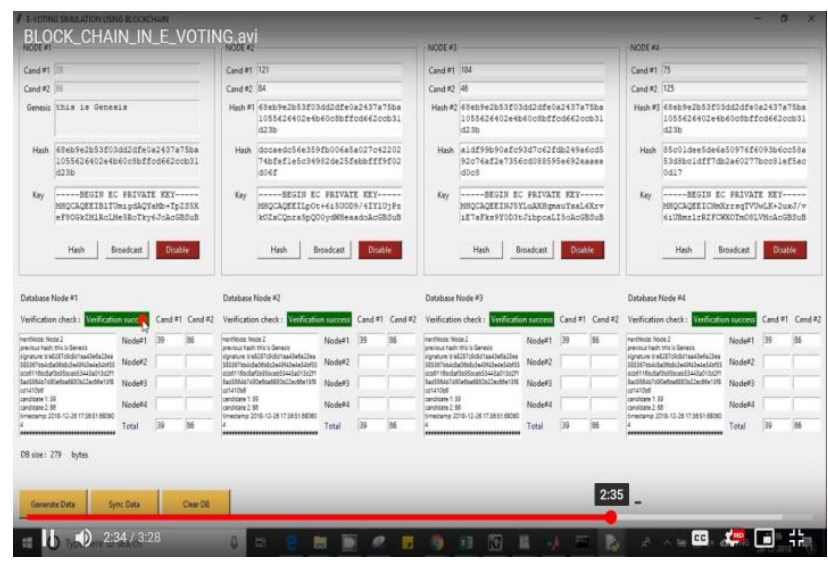

Fig 4.3: DATA

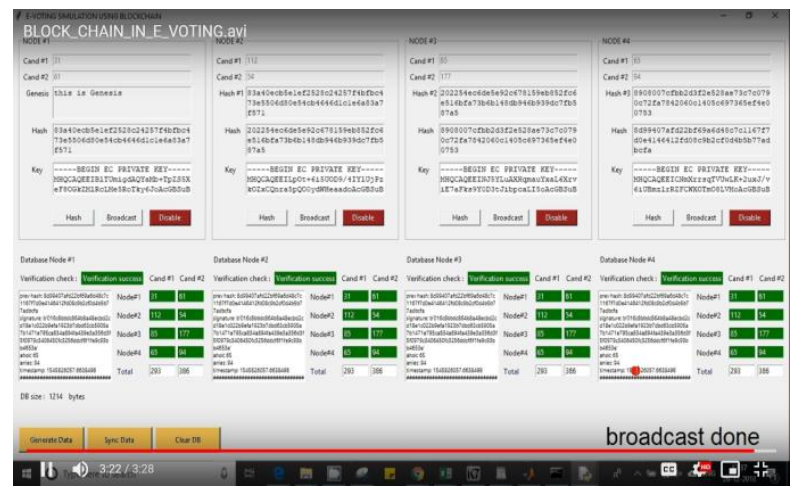

Fig 4.4: Broadcast Done

\section{CONCLUSION}

Adapting advanced casting a ballot frameworks to make the open discretionary procedure less expensive, quicker and simpler, is a convincing one in present day society. Making the constituent procedure shoddy and brisk, standardizes it according to the voters, evacuates a specific power boundary between the voter and the chosen authority and puts a specific measure of weight on the chosen authority. It additionally opens the entryway for a more straightforward type of popular government, enabling voters to express their will on individual bills and suggestions.

\section{REFERENCES}

1. Sos.ca.gov. (2007). Top-to-Bottom Review | California Secretary of State. Available at: http://www.sos.ca.gov/elections/voting-systems/ oversight/ top-bottom-review/.

2. Nicholas Weaver. (2016). Secure the Vote Today. Available at:https:// www.lawfareblog.com/ secure-vote-today.

3. TechCrunch, (2018). Liquid democracy uses blockchain to fix politics, and now you can vote for it [Online]. Available at: https://techcrunch. $\quad$ com/2018/02/24/liquid-democracy-usesblockchain/

4. Geth.ethereum.org. (2018). Go Ethereum. Available at: https://geth. ethereum.org/

5. VitalikButerin. (2015). Ethereum White Paper. Available at: https:// github.com/ethereum/wiki/wiki/White-Paper.

6. Sajeev Ram, Shylaja, Arun sahayadhas, "CAD system: a content based image retrieval approach for pulmonary nodule detection in CT images", International Journal of Engineering \& Technology, Vol.7, (2.21), pp301-305, 2018

7. Nca.tandfonline.com. (2015). Pirates on the Liquid Shores of Liberal Democracy: Movement Frames of European Pirate Parties. [Online]. Available at: https://nca.tandfonline.com/doi/abs/10.1080/ 13183222.2015.1017264\#.Wr0zCnVl8YR

8. Feng Hao, P.Y.A. Ryan and Piotr Zielinski. (2008). Anonymous voting by two-round public discussion. Available at:http://homepages.cs.ncl.ac. uk/feng.hao/files/OpenVote_IET.pdf

9. Feng Hao and Piotr Zielinski. A 2-Round Anonymous Veto Protocol Available at: http://homepages.cs.ncl.ac.uk/feng.hao/files/av_net.pdf.

\section{AUTHORS PROFILE:}

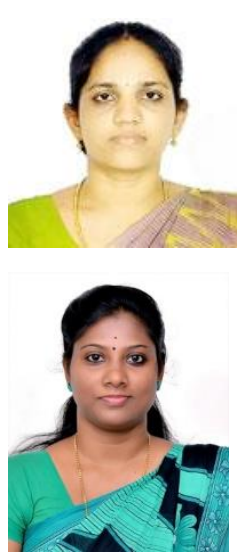

P.SheelaGowr, Assistant Professor, Department of Computer Science and Engineering, Vels Institute of Science, Technology and advanced Studies, Chennai, India. Area of Research : Cloud Computing and Networking.

M.Latha, Assistant Professor, Department of Computer Science and Engineering, Vels Institute of Science , Technology and advanced Studies, Chennai, India. Area of Research : Medical Imaging 